\title{
EL PROCEDIMIENTO DE ENMIENDA CONSTITUCIONAL EN LAS CONSTITUCIONES ESTATALES DE ESTADOS UNIDOS: PARTICULARIDADES DE LOS PROCESOS Y MECANISMOS DE PARTICIPACIÓN CIUDADANA ${ }^{1}$
}

\author{
ROBERTO VICIANO PASTOR \\ Catedrático de Derecho Constitucional \\ Universitat de València \\ DIEGO GONZÁLEZ CADENAS \\ Profesor Ayudante Doctor de Derecho Constitucional \\ Universitat de València
}

TRC, núm. 46, 2020, pp. 485-509

ISSN 1139-5583

\section{SUMARIO}

I. Introducción. II. El procedimiento de enmienda constitucional impulsado por el legislativo. III. El procedimiento de enmienda constitucional impulsado por los ciudadanos. IV. El procedimiento de enmienda constitucional mediante una Comisión automáticamente creada en forma periódica: el caso de Florida. V. Conclusiones.

\section{INTRODUCCIÓN}

En Estados Unidos existen dos mecanismos de cambio constitucional previstos en las constituciones de los estados miembros: las enmiendas ${ }^{2}$ y las revisiones

1 Esta investigación es fruto de sendas estancias de investigación realizadas por los autores en el Real Colegio Complutense en la Universidad de Harvard, instituciones a las que agradecemos su hospitalidad pues sin el acceso a los fondos bibliográficos de dicha Universidad no hubiera sido posible la realización de este trabajo. Y, por supuesto, agradecer a la Universitat de València que financiara dichas estadías con sendas becas de investigación, que en el caso del profesor González Cadenas tomaron la forma de una estancia posdoctoral en el Institute for Global Law and Policy de dicha Universidad, que se extendió durante dos cursos académicos.

2 A pesar de que constitutional amendment podría ser traducido como reforma constitucional parcial para acercarlo más al vocabulario constitucional español, nos ha parecido apropiado utilizar «enmienda constitucional», no 
constitucionales. Las primeras son reformas parciales de la Constitución que no afectan a alguna de sus partes esenciales, mientras que las segundas son aquellas que tienen por objeto reconsiderar aspectos fundamentales del sistema constitucional o el reemplazo de una Constitución por otra y requieren, salvo contadas excepciones, de la convocatoria de una convención constitucional ${ }^{3}$. Esta diferenciación, ciertamente, ha generado y genera múltiples litigios en los tribunales debido a la insuficiente definición de sus contornos ${ }^{4}$. Pero, más allá de eso, como indica el título de este trabajo, y por razón de espacio, nos vamos a ocupar en este caso únicamente de los mecanismos de enmienda constitucional, dejando para otra investigación, que tiene su entidad propia, los mecanismos de revisión constitucional de aspectos nucleares del contenido del texto constitucional o la activación de una convención constitucional con el propósito de aprobar una nueva constitución.

sólo para mantenernos más cercanos al concepto en su lengua original, sino también puesto que en el constitucionalismo de lengua española dicha terminología puede encontrarse, por ejemplo, en la diferenciación entre enmienda constitucional y reforma de la constitución en la Constitución ecuatoriana de 2008.

3 Cain, B.E., Noll, R.G., «Malleable Constitutions: Reflections on State Constitutional Reform», Texas Law Review, vol. 87, 2009, p. 1522; Jameson, J.A., A treatise on constitutional conventions : their history, powers, and modes of proceeding. Chicago: Callaghan, 1887, p. 546. Nótese que en este texto utilizamos una traducción directa del término constitutional convention. En la terminología en lengua española, el concepto suele denominarse asamblea o convención constituyente, diferenciándose en sus poderes de las convenciones o asambleas constitucionales.

4 La no diferenciación clara entre aquellos aspectos que requieren de una revisión y, por lo tanto, de la convocatoria de una convención constitucional, y de aquellos preceptos que pueden ser modificados a través del procedimiento de enmienda constitucional, ha sido objeto de litigio en múltiples ocasiones al considerarse que se había procedido a realizar una revisión constitucional a través del método menos agravado de la enmienda constitucional. Los pleitos por esta causa han sido especialmente numerosos en California. Así, por ejemplo, en Raven v. Deukmejian, resuelto por el TS de Californiael 24 de diciembre de 1990, se determinó que una iniciativa popular de enmienda constitucional ratificada popularmente destinada a realizar toda una serie de cambios de importancia en materia penal, debía ser invalidada dado que al alterar en gran medida el esquema constitucional constituía una revisión de la Constitución y únicamente está legitimado para iniciar el proceso de revisión de la Constitución de California el legislativo. El principio que siguió el Tribunal es que cualquier cambio constitucional substancial, ya sea a nivel cuantitativo o cualitativo, constituye una revisión constitucional. Veáse al respecto Goldberg, J., «Raven v. Deukmejian: A Modern Guide to the Voter Initiative Process and State Constitutional Independence», San Diego Law Review, vol. 28, 1991. En similar sentido, el TS de Florida defendió el 21 de diciembre de 1970 en Adams v. Gunter que una iniciativa popular de enmienda constitucional cuyo objeto era convertir el legislativo en unicameral no podía ser sometida a votación puesto que constituía una revisión de la Constitución y ésta no se podía llevar a cabo a través de una iniciativa popular. Otros casos, como McFadden v. Jordan, resuelto por el TS de California el 3 de agosto de 1948, revistieron, aparentemente, menos complicación. El TS, realizó aquí un análisis cuantitativo dado que la iniciativa propuesta contenía 21.000 palabras, mientras que la Constitución por aquel entonces vigente, de 1879, tenía un total de 55.000 y alteraba 15 de los 25 artículos de la Constitución. Por el contrario, el TS de California defendió en 2009 en Strauss $v$. Horton que la enmienda constitucional ratificada popularmente que reconocía únicamente el matrimonio entre un hombre y una mujer era efectivamente una enmienda y no una revisión constitucional. En palabras del TS: «Como un asunto cuantitativo, los demandantes admiten que la Proposición 8, que agrega solo una sección simple a la constitución, no constituye una revisión. Como un asunto cualitativo, el acto de limitar el acceso a la designación de matrimonio a parejas del sexo opuesto no tiene un efecto sustancial o, incluso, mínimo en el marco gubernamental de California que existía antes de la enmienda». Veáse WiLliams, R.F., The Law of American State Constitutions. New York: Oxford University Press, 2009, p. 403. 
Hoy día, la gran mayoría de constitucionales estatales, con notables excepciones como el caso de Massachusetts, establecen los mecanismos, con múltiples particularidades, para que se pueda proceder a la vía de reformar la constitución estatal a través de una enmienda o de la convocatoria de una convención constitucional $^{5}$. Asimismo, para que pueda entrar en vigor cualquier enmienda o revisión constitucional, con la única excepción del estado de Delaware, donde el legislativo puede enmendar la Constitución sin necesidad de un referéndum de ratificación ${ }^{6}$,

5 No obstante, esto no siempre fue así. Las primeras constitucionales prefederales establecían bien un único método de reforma constitucional, ya fuera a través de una convención constitucional (caso de Pensilvania, Vermont, Georgia, Massachusetts y la Constitución de New Hampshire de 1784) o de una enmienda constitucional propuesta por el legislativo (Maryland, Delaware y la Constitución de Carolina del Sur de 1778), bien no contenían provisión alguna para modificar el texto constitucional. Durante el siglo xix se fue, progresivamente, tendiendo hacia textos constitucionales en los que ambas vías fueran posibles, si bien todavía hoy día, caso por ejemplo de Massachusetts, algún texto constitucional no contempla la posibilidad de convocatoria de una convención constitucional. Véase DoDD, W.F., The Revision and Amendment of State Constitutions. Baltimore: The John Hopkins Press, 1910, p. 118. Aquí jugó ciertamente un papel de importancia la conocida como Rebelión de Dorr en el Rhode Island de los años 1840, consecuencia de la imposibilidad de reformar por ninguna vía la Carta Constitucional que por aquel entonces regía el ordenamiento de aquel estado. Los eventos que sacudieron Providence calaron en el imaginario colectivo. Una parte mayoritaria de las élites políticas comprendió que era necesario generar mecanismos de cambio constitucional que pudieran canalizar las peticiones populares y evitar que éstas terminaran expresándose fuera de los cauces establecidos. A partir de entonces se empezaron a establecer procedimientos de enmienda constitucional en aquellas constituciones estatales que no los tenían, se facilitó la activación de los ya existentes y se allanó el camino para que pudiera convocarse una convención constitucional. Al terminar el siglo, todos los estados, con la excepción de New Hampshire, introdujeron en sus textos constitucionales procedimientos de enmienda constitucional. Véase Dinan, J. «"The Earth Belongs Always to the Living Generation”: The Development of State Constitutional Amendment and Revision Procedures», The Review of Politics, vol. 62, n. ${ }^{\circ} 4$, 2000, p. 654. Para más información al respecto de la rebelión capitaneada por Thomas Dorr, se recomienda la lectura de GETTLEMAN, M.E., The Dorr Rebellion. A study in American Radicalism: 1833-1849. New York: Randon House, 1973; Fritz, C.G., American Sovereigns: The People and America's Constitutional Tradition before the Civil War. New York: Cambridge University Press, 2008, p. 256.

6 La vigente Constitución de Delaware resultó de la Convención Constitucional que tuvo lugar entre 1896 y 1897 en la ciudad de Dover. A primera vista, se podría pensar que debido a las fechas en que tuvo lugar la Convención, puede resultar normal que ésta no terminara incluyendo el requisito del referéndum de ratificación. No obstante, en la Constitución de 1852 que la Convención Constitucional de Delaware sometió a referéndum en 1853 y resultó rechazada por los ciudadanos, se incluía la obligatoriedad de llevar a cabo un referéndum de ratificación en caso de enmienda constitucional. Esto es, más de cuarenta años atrás una mayoría de constituyentes de Delaware ya se mostró favorable a la inclusión de un precepto de estas características. La regulación aprobada en 1897 no fue entonces consecuencia de un debate que se podría pensar todavía inexistente en aquella época. Al contrario, ha de tenerse en cuenta que en 1852 la fuerza ideológica de lo que se ha venido llamando democracia o era jacksoniana, en referencia a Andrew Jackson, a la sazón decimoséptimo presidente federal y un firme defensor de la participación ciudadana directa, era fuerte. Véase HoLLAND, R.J., The Delaware State Constitution. New York: Oxford University Press, 2017, p. 16. El debate en 1897 acerca del artículo XVI que regula el proceso de enmienda constitucional es, en ese sentido, ilustrativo de hasta qué punto, al menos entre los constituyentes de Delaware y de acuerdo a la lectura que podemos hacer de sus debates, se desconocía o se obviaba una concepción de Constitución como necesario reflejo de la expresión directa de la soberanía popular. En los largos debates que se produjeron al respecto ninguno de los constituyentes expresó esta idea. Los constituyentes defendían que, efectivamente, una Constitución ha de ser el reflejo de la voluntad popular, pero que no necesariamente ésta debía expresarse en forma directa para comprobar si era así. De acuerdo con su punto de vista, el legislativo podía subrogarse en dicho papel, de tal forma que si los ciudadanos votaban en unas elecciones legislativas conociendo la propuesta de enmienda 
es preceptiva la aquiescencia directa de la ciudadanía ante cualquier modificación parcial o total del texto constitucional. No debe extrañar este diseño constitucional a la vista de cómo la teoría y práctica constitucional estadounidense ha ido entendiendo desde sus orígenes el concepto de Constitución como norma suprema reflejo de la voluntad popular ${ }^{7}$. Así, por ejemplo, en la Convención Constitucional de Montana en 1972 se produjo un debate acerca de la posibilidad de que el legislativo pudiera llevar a cabo enmiendas constitucionales sin necesidad de ratificación popular. Algunos representantes defendieron que debía dejarse la puerta abierta a introducir enmiendas constitucionales sin la aprobación directa de la ciudadanía. Desde su punto de vista, era innecesario iniciar un procedimiento electoral, con los costes que lleva aparejado, dado el alto grado de dificultad que podría suponer la comprensión de algunas enmiendas o la posibilidad de que éstas pudieran versar sobre cuestiones meramente técnicas. La postura mayoritaria fue, sin embargo, bien diferente. Uno de los delegados de la convención, George Harper, señaló que para hacer cumplir efectivamente el principio de acuerdo con el cual el texto constitucional pertenece al pueblo y es el reflejo de su voluntad, «toda palabra que esté en el mismo debe ser votada por el pueblo» ${ }^{8}$. De esta forma, los ciu-

constitucional de antemano y si dos tercios de los representantes eran favorables a la misma, era claro que una mayoría del pueblo era igualmente favorable a la reforma. Al respecto, consúltense en los cinco volúmenes de recopilación de debates y votaciones de la Convención de Delaware, los debates de los días 14 de abril (pp. 2392 y ss) y 17 de mayo de 1897 (pp. 2971 y ss.) en Hardesty, E.C., GuYer, C.G., Debates and proceedings of the constitutional convention of the state of Delaware. Dover: Supreme Court of Delaware, 1958 Para encontrar una referencia acerca del sustrato ideológico del tal punto de vista, habremos de remitirnos a otra parte de los debates en la Convención, la relativa a la posibilidad de que fuera obligatorio contar con la aquiescencia directa del pueblo para que el estado se endeudara. Uno de los constituyentes objetó que: «tenemos ahora establecido el referéndum para algunas materias, pero muy, muy pocas. Estoy completamente en contra de su extensión. Esto no es una democracia, es una forma republicana de gobierno; y nuestras leyes están hechas por nuestros representantes. Queremos tantos controles sobre ellos como podamos razonablemente tener. No creo que debamos manifestar, por lo que hacemos aquí, una falta total de confianza en la Asamblea General, porque, después de todo, es, y debe seguir siendo, nuestro poder legislativo, y no sería justo que nosotros debemos expresar en la Constitución nuestro desprecio por las legislaturas que debemos tener en el futuro. [...] Hay personas entre nosotros que quieren un referéndum para todo tipo de asuntos, pero eso supondría la destrucción práctica de nuestra forma republicana de gobierno. No creo en eso. No creo que las personas, en su capacidad agregada, sean competentes para legislar. El principio de referéndum es bueno en comunidades pequeñas, sobre asuntos menores. Reconozco las muchas ventajas del sistema de town meetings de Nueva Inglaterra para la consideración de los asuntos locales, donde la gente se reúne y los considera y vota. Creo que esa práctica en las zonas rurales de Nueva Inglaterra ha sido probablemente una de las cosas más beneficiosas que han tenido. Thomas Jefferson pensó que ello era un excelente mecanismo educador de las personas en el autogobierno. Pero sé que incluso en Nueva Inglaterra, tan pronto como el pueblo se convierte en una ciudad, están obligados a abandonar esa práctica. Cada vez que un pueblo crece hasta quince, veinte o treinta mil habitantes, tienen que abandonarlo, porque no pueden reunir a la gente en su capacidad agregada para considerar estos asuntos». Véase el debate del 8 de marzo de 1897 en Hardesty, GuYer, cit., p. 1419.

7 Handlin, O., Handlin, M., The popular sources of political authority. Documents on the Massachusetts Constitution of 1780. Cambridge: Harvard University Press, 1966; AdAms, W.P., The First American Constitutions. Lanham (MD): A Madison House Book, 2001; LuTz, D.S., Popular consent and popular control: Whigh Political Tehory in the Early State Constitutions. Baton Rouge: Louisina State University Press, 1980.

8 Johnstone, A., «The Constitutional Initiative in Montana», Montana Law Review, vol. 71, 2010, p. 343 . 
dadanos han rechazado en múltiples ocasiones propuestas de enmiendas a su texto constitucional, como, por citar sólo algunos ejemplos, el caso de Florida en 1977 y 1998, o las nuevas constituciones resultantes de una convención constitucional, como la de Nueva York en 1967, Rhode Island y Maryland en 1968 o Nuevo México y Arkansas en 1970.

Los mecanismos de democracia directa existentes en EEUU han captado escasamente la atención de la academia española. Que tengamos conocimiento, no hay ningún artículo doctrinal en español dedicado exclusivamente al estudio de los mecanismos relativos al cambio constitucional estatal ${ }^{9}$. Esta investigación tiene por objetivo colmar dicho vacío y ofrecer una perspectiva general de los mismos y de los principales debates jurídicos. En Estados Unidos, debido al elevado número ${ }^{10}$ y a la importancia de los preceptos constitucionales que han sido sometidos a votación, existe una rica bibliografía al respecto cuyos principales textos, por lo que respecta en este caso únicamente a los mecanismos de enmienda constitucional, se reseñarán aquí. Sólo desde inicios del presente siglo se han introducido en diferentes constitucionales estatales, a través de iniciativas populares, preceptos como aumentos del salario mínimo, del impuesto sobre la renta a las rentas altas, del gasto público en educación, eliminación del impuesto sobre sucesiones, fijación de una mayoría de dos tercios en el legislativo para la aprobación de aumento de impuestos, modificación del proceso por el que se diseñan los colegios electorales o de legalización de la marihuana recreacional ${ }^{11}$. Sin ir más lejos, en las midterms de noviembre de 2018, en el estado de Florida, por ejemplo, se plantearon a la ciudadanía dos propuestas de enmienda constitucional por ini-

9 La exhaustiva tesis doctoral de V. Manuel Cuesta López dedicada a la iniciativa legislativa popular referencia en varios de sus puntos el procedimiento de iniciativa popular en Estados Unidos. No obstante, en el capítulo que dedica a la experiencia comparada trata igualmente el ejemplo de otros países, lo cual resta lógicamente espacio y detalles al caso que aquí nos ocupa. El análisis que realiza de EEUU se centra en gran medida, además, en California y Massachusetts, siendo la casuística mucho más amplia y variada. Igualmente, como es claro por la propia temática de la tesis, entra únicamente al análisis de la iniciativa popular, dejando de lado las diversas posibilidades de reforma. Véase Cuesta López, V.M. Participación directa e iniciativa legislativa del ciudadano en democracia constitucional. En similar sentido, C. Garrido López dedica también un espacio de su reciente investigación al instituto de la iniciativa legislativa popular en Estados Unidos. Véase GARRIDO López, C., «La iniciativa popular de referéndum», Teoria y Realidad Constitucional, n. ${ }^{\circ}$ 43, 2019, pp. 317-345. Recientemente, E. Seijas Villadangos ha publicado un excelente artículo acerca del papel de las constituciones estatales de Estados Unidos en el cual dedica un breve apartado a su procedimiento de cambio constitucional. Véase Seijas Villadangos, E., «Las constituciones de los estados federados; en particular las de los estados norteamericanos», Teoria y Realidad Constitucional, n. ${ }^{\circ}$ 44, 2019, pp. 271-308. Realiza asimismo una breve introducción al asunto que aquí nos ocupa el working paper de RoDÉs MATEU, A. Una visión introductoria sobre la democracia directa en Estados Unidos.

10 Desde que se introdujo en diferentes constituciones estatales el mecanismo de iniciativa popular de reforma constitucional hasta el año 2014, se sometieron a consideración de los ciudadanos 1965 propuestas. Véase Dinan, J., «State Constitutional Initiative Processes and Governance in the Twenty-First Century», Chapman Law Review, vol. 19, n. ${ }^{\circ}$ 1, 2016, p. 63 y https://ballotpedia.org/Initiative_frequency_of_ constitutional_amendments_related_to_time_for_signature_collection

11 Dinan, «State Constitutional Initiative Processes and Governance in the Twenty-First Century», p. 67. 
ciativa popular. En estas se preguntó acerca de la necesidad de aprobación directa popular para autorizar casinos de juego en el estado y sobre la restauración del derecho al voto a ciudadanos que hubieren cumplido penas de prisión por delitos graves. En ambos casos las propuestas fueran aprobadas por amplia mayoría y generaron un amplio debate social.

En suma, en este artículo, se desarrollarán los mecanismos por los cuales se procede a la enmienda constitucional en los estados de Estados Unidos. Estos, a su vez, se han dividido en tres apartados. En el primero de ellos, que es el más sencillo, nos centraremos en conocer el procedimiento que parte del impulso del legislativo. En segundo lugar, dedicaremos un espacio mayor a exponer las particularidades de aquellos procedimientos de enmienda constitucional impulsados por la propia ciudadanía. Por último, se hará hincapié en un modo de reforma constitucional único en toda la nación: la creación en forma periódica y automática de una comisión que tiene por objeto plantear directamente propuestas de enmienda constitucional a los ciudadanos de Florida.

\section{EL PROCEDIMIENTO DE ENMIENDA CONSTITUCIONAL IMPULSADO POR EL LEGISLATIVO}

Todos los legislativos estatales están facultados para iniciar un proceso de enmienda constitucional, la cual, de prosperar, deberá ser sometida a la consideración de los ciudadanos, con la excepción, como ya se ha indicado, del estado de Delaware $^{12}$. Generalmente, cualquier representante en cualquiera de las dos cámaras está facultado para iniciar el procedimiento y plantear su debate y votación ${ }^{13}$. Algunos estados, no obstante, requieren que antes de proceder al debate y votación, se lleve a cabo una audiencia pública ${ }^{14}$. Las mayorías para la aprobación de la propuesta de enmienda son igualmente variables. La mayoría de estados permiten que las dos cámaras en un mismo periodo de sesiones aprueben una proposición de enmienda ${ }^{15}$. Entre estos, debe distinguirse una minoría de estados, que requieren únicamente una mayoría absoluta ${ }^{16}$ y aquellos que requieren mayorías de tres quintos ${ }^{17} \mathrm{o}$ dos tercios ${ }^{18}$. Por otra parte, determinados estados exigen

12 Benjamin, G., «Constitutional Amendment and Revision». En Tarr, A.G., Williams, R.F., eds. State Constitutions for the Twenty-first Century, Volume 3. Albany: State University of New York Press, 2006

13 En California el proceso de presentación de una enmienda constitucional por el legislativo es en ese sentido igual al de presentación de una ley ordinaria. California, Standing Rules of the Assembly, artículos 46 y siguientes.

14 Cfr. Constitución de Nueva Jersey, artículo IX.

15 Téngase en cuenta que un periodo de sesiones tiene una duración máxima de un año. Pueden consultarse datos al respecto actualizados semanalmente en: https://ballotpedia.org/State_legislative_sessions

16 Cfr. Constitución de Oklahoma, artículo XXIV, sección 1.

17 Constitución de Illinois, artículo XIV, sección 2.

18 Cfr. Constitución de Colorado, artículo XIX, sección 2. 
que la propuesta de enmienda sea aprobada en dos periodos de sesiones consecu$\operatorname{tivos}^{19}$. Algunos estados, incluso, permiten dos sistemas de votación: bien se aprueba por amplia mayoría en el primer periodo de sesiones, bien se aprueba por una mayoría absoluta en dos periodos de sesiones ${ }^{20}$.

Una vez aprobada la propuesta de enmienda, debe procederse a la redacción del título y el texto que se someterá a consideración de los ciudadanos en la papeleta de voto. De ello se suele encargar algún cargo público. Si bien es habitual que dicha tarea se encomiende al secretario de estado ${ }^{21}$, en algunos estados es el fiscal general $^{22}$, mientras que en otros se encarga el vicegobernador ${ }^{23}$, varios cargos a la vez ${ }^{24}$ o un consejo compuesto por el secretario de estado y cuatro miembros más, de los cuales dos no pueden pertenecer al mismo partido político ${ }^{25}$. Redactada la propuesta y habiéndose dejado un tiempo para publicitarla debidamente ${ }^{26}$, pasa

19 Aquí, a su vez, las mayorías son también variables. La mayoría de los doce estados que establecen este requisito requieren una mayoría absoluta en dos sesiones consecutivas. Véase, por ejemplo, el artículo XII, sección 1, de la Constitución de Wisconsin. Los estados restantes requieren de mayorías más agravadas. Así, por ejemplo, en Tennessee se requiere aprobación por mayoría absoluta en ambas cámaras en la primera sesión, mientras que la segunda requiere de dos tercios. Véase el artículo XI, sección 3 de la Constitución del citado estado.

20 Es el caso de Connecticut, que requiere en un único periodo de sesiones de tres cuartos de los votos del total de los miembros en cada cámara o de una mayoría absoluta en dos periodos de sesiones consecutivos (Constitución de Connecticut, artículo XII). En similar sentido, Hawái requiere en una única sesión dos tercios (artículo XVII, sección 3 de su Constitución) y Nueva Jersey tres quintos (artículo IX de su Constitución). Pensilvania requiere también dos tercios en una única sesión, aunque sólo «en el caso de que una emergencia importante amenace o esté a punto de amenazar a la Commonwealth» (artículo XI, sección 1 de su Constitución).

21 Téngase en cuenta que el secretario de estado a nivel estatal no ocupa funciones similares a las del cargo homónimo a nivel federal, encargado de los asuntos con el extranjero. A nivel estatal, el secretario de estado suele ser el encargado, entre otras funciones, de los procesos electorales. Por lo que respecta a sus funciones a la hora de redactar el título y el resumen, puede tomarse como ejemplo el Código Electoral de Maine en su capítulo 11, párrafo 906.

22 Cfr. Código Electoral de California, división 9, capítulo 1, artículo 5.

23 Cfr. Constitución de Alaska, artículo XIII, sección 1.

24 La Constitución de Georgia establece en su artículo X, sección 1, párrafo II, que el resumen de la propuesta de enmienda constitucional lo deben preparar el secretario de estado, el fiscal general del estado y el Consejo Legislativo del estado, un departamento adjunto al legislativo que da asesoramiento legal.

25 Es el caso de Ohio. Véase el artículo XVI, sección 1 de su Constitución.

26 Muchas constituciones determinan el tiempo máximo que tiene el legislativo para plantear una propuesta de enmienda constitucional antes de las próximas elecciones. Dicho periodo oscila entre los seis meses que requiere el artículo XIX, sección 22 de la Constitución de Arkansas y el mes que establece el artículo XIV, sección 2 de la Constitución de Illinois. Es común, no obstante, que el plazo máximo sea de 90 días, como en el caso de la Constitución de Arizona (artículo 21, sección 1) o la de Iowa (artículo X, sección 1). Ese tiempo debe aprovecharse para publicitar la propuesta, por lo que muchas constituciones determinan también los mínimos para que esto se produzca adecuadamente. En el citado artículo de la Constitución de Arizona se señala también que la propuesta debe publicitarse en al menos un periódico de cada uno de los condados. Provisión que añaden en igual forma constituciones como la de Arkansas (artículo XIX, sección 22), la de Hawái referida a los distritos senatoriales (artículo XVII, sección 3) o la de Nebraska añadiendo además que debe publicarse una vez durante tres semanas consecutivas (artículo XVI, sección 1). La Constitución de Missouri (artículo XII, sección 2 b) va un paso más allá y requiere que se publique en dos periódicos de diferente tendencia en cada uno de los condados una vez por semana en dos semanas consecutivas, siendo la última 
entonces a incluirse en la papeleta de voto de las siguientes elecciones o de unas elecciones especialmente dedicadas a la propuesta de enmienda constitucional ${ }^{27}$. Basta por el momento saber que para su aprobación se requiere un porcentaje de voto variable en los diferentes estados y alguna otra especificad relativa al caso de las enmiendas que afecten únicamente a alguna parte del estado. En caso de cumplir con los requisitos establecidos, la enmienda entrará en vigor en el momento determinado en la Constitución o en el momento que la propia enmienda establezca $^{28}$.

\section{EL PROCEDIMIENTO DE ENMIENDA CONSTITUCIONAL IMPULSADO POR LOS CIUDADANOS}

Detallado el procedimiento más sencillo por el que se procede a introducir una enmienda constitucional, veámoslo añadiendo la variable de la iniciativa popular para la enmienda de la constitución que han introducido dieciocho esta$\operatorname{dos}^{29}$. Debe, en primer lugar, tenerse presente que la initiative es considerada una expresión del derecho a la libertad de expresión y está, por lo tanto, amparada por la primera y la decimocuarta enmienda de la Constitución federal ${ }^{30}$. En segundo

publicación no más de 30 días y no menos de 15 antes de la elección. En caso de que sólo haya un periódico en un condado, debe publicitarse una vez en cuatro semanas consecutivas. La Constitución de Nuevo México incluye, además, una disposición única en su artículo XIX, sección 1, de acuerdo con la cual debe publicarse la enmienda también en español. Señala además que el secretario de estado deberá hacer «esfuerzos razonables para notificar el contenido y el propósito de las enmiendas constitucionales aprobadas legislativamente en idiomas indígenas y a grupos de idiomas minoritarios.»

27 Una buena parte de constituciones determinan que la votación podrá llevarse a cabo bien en una elección general, estatal o federal, o bien en una especial. Véase, por ejemplo, el artículo XIII, sección 1, de la Constitución de Luisiana, el artículo XII, sección 1, de la Constitución de Michigan o el artículo XVIII, sección 284 de la Constitución de Alabama. No obstante, algunas obligan a que sea para la próxima elección general. Es el caso, por ejemplo, de Kentucky, cuya Constitución establece en su sección 256 que la votación deberá tener lugar en la siguiente elección general a miembros de la cámara de representantes. La Constitución de Virginia Occidental incluye una disposición única de acuerdo con la cual, de decidir el legislativo que la votación sobre la o las enmiendas constitucionales propuestas tenga lugar en una elección especial, no podrá votarse cualquier otra cuestión (véase su artículo XIV, sección 2).

28 La Constitución de Alaska en su artículo XIII, sección 1, señala que a menos que se disponga lo contrario en la enmienda, ésta entrará en vigencia treinta días después de que el vicegobernador certifique las elecciones. La Constitución de Georgia determina en su artículo X, párrafo X, que a menos que la enmienda establezca lo contrario, entrará en vigor el primer día de enero tras su ratificación.

29 Dichos estados son Arizona, Arkansas, California, Colorado, Dakota del Norte, Dakota del Sur, Florida, Illinois, Massachusetts, Michigan, Mississippi, Missouri, Montana, Nebraska, Nevada, Ohio, Oklahoma y Oregón.

30 En Buckley v. American Constitutional Law Foundation, Inc., resuelto el 12 de enero de 1999, se planteó al Tribunal Supremo federal un caso acerca de la regulación de la iniciativa popular en Colorado. La ley vigente por aquel entonces normaba determinados límites para proceder a la recogida de firmas. Se requería que quien lo hiciera estuviera registrado como votante y tuviera al menos dieciocho años; se limitaba a seis meses el periodo para proceder a la recogida de firmas, se demandaba la firma de una declaración jurada, la identificación mediante una tarjeta en la que se señalara, en caso de estar pagados para realizar dicha labor, el 
lugar, ha de subrayarse que la initiative es una iniciativa popular en la que los ciudadanos platean directa, o indirectamente en el caso de Massachusetts ${ }^{31}$, una enmienda constitucional a sus conciudadanos. Los mal llamados mecanismos de iniciativa popular regulados en los ordenamientos de diferentes Estados miembros de la Unión Europea, como es el caso de España, pueden encuadrarse en lo que la literatura especializada ha denominado iniciativas de agenda ${ }^{32}$. En este tipo de iniciativas, la decisión última recae sobre el legislativo, el cual tiene la capacidad de decidir si admite a trámite dicha iniciativa y, en su caso, enmen-

nombre y teléfono del empleador; y se obligaba a que los empleadores informaran mensualmente acerca de sus empleados. Cuando el caso llegó al Tribunal Supremo, se había dado parcialmente la razón al estado al reconocer la constitucionalidad de los requisitos de edad, la declaración jurada y el tiempo máximo de recogida de firmas. No obstante, el requisito de registro como votante, la identificación y el informe mensual fueron declarados parcialmente inconstitucionales por el Tribunal de Apelaciones para el Décimo Circuito. Finalmente, el Tribunal Supremo federal dio la razón al Tribunal de apelación al considerar que se trataba de requisitos que limitaban en forma excesivamente severa el derecho a la libertad de expresión. En concreto, consideraron, por lo que respecta a la obligatoriedad del registro como votante, que la recolección de firmas para una iniciativa es independiente de la voluntad de ejercer el derecho al sufragio y limita, por tanto, el derecho a la libertad de expresión. En cuanto a la necesidad de identificación, el Tribunal consideró que la obligación de hacer pública la identidad del recolector de firmas limitaba también excesivamente su derecho a transmitir un mensaje político al poder sentirse cohibido, desalentar la participación y no garantizar la expresión política desde el anonimato. Sin embargo, la obligatoriedad de que la identificación incluyera el nombre del empleador, en caso de existir, no se entró a dirimir, al no formar parte de las peticiones de los demandantes. En directa relación con ello, el Tribunal consideró que obligar al empleador a identificar a sus trabajadores violentaba su anonimato. En Yes on Term Limits $v$. Savage, un tribunal federal, en este caso el Tribunal de apelaciones del Décimo Circuito, sí entró a delimitar, por petición de los demandantes, a diferencia del anterior caso, si el requisito de residencia en Oklahoma para recolectar firmas es inconstitucional. El Tribunal, en su sentencia de 18 de diciembre de 2008, partió de la base de que «la circulación de una petición es una práctica nuclear del discurso político al implicar una comunicación interactiva sobre el cambio político. En consecuencia, la protección de la primera enmienda para esta actividad es central». En ese sentido, debe llevarse a cabo un escrutinio estricto de los límites que se impongan al ejercicio del derecho. Desde el punto de vista del estado, se trataba de una regulación establecida para prevenir el fraude. Resulta complejo, argumentaron, localizar a los no residentes en caso de que se produzca alguna infracción dado que el estado no está facultado para citarlos. No obstante, el Tribunal defendió que, incluso aceptando como válida esa aserción, la regulación no se ajustaba al principio de acuerdo con el cual una norma debe estar diseñada para cumplir únicamente con los objetivos que se marca (narrow tailoring) al poder regular otras alternativas para evitar el problema señalado (como presentar acciones penales en caso de que un recolector de firmas no acudiese a una citación al haber aceptado previamente a su labor que debería hacerlo en caso de ser solicitado). Ello llevó al Tribunal a considerar que se había violentado la primera y la decimocuarta enmienda de la Constitución federal.

31 De acuerdo con la Constitución de Massachusetts, una iniciativa popular de enmienda constitucional únicamente puede ser sometida a votación si ha sido aprobada por al menos un veinticinco por ciento del legislativo en dos periodos de sesiones consecutivos. El objetivo de esta disposición es asegurar que las iniciativas populares cuentan con un apoyo significativo entre los representantes de la ciudadanía. No obstante, el legislativo ha utilizado esa facultad para evitar el voto de determinadas peticiones. Así lo hizo, por ejemplo, en relación con una iniciativa que tenía por objeto limitar el matrimonio a la unión entre un hombre y una mujer. Dicho caso fue resuelto por el TS de Massachusetts en diciembre de 2006. En Doyle v. Secretary of the Commonwealth, el Tribunal señaló que de acuerdo a una lectura literal del texto constitucional los legisladores no estaban obligados a proceder al voto y, por tanto, el Tribunal no tenía capacidad para ordenar al legislativo que lo hiciera.

32 BÁez Lechuga, I., Análisis jurídico-político de la Iniciativa Ciudadana Europea en el contexto de un equilibrio institucional complejo: posibles efectos dinamizadores de la democracia a partir de la introducción de la iniciativa ciudadana en la Unión Europea. Madrid: Agencia Estatal Boletín Oficial del Estado, 2016, p. 283. 
darla a voluntad. Además, los electores no tienen opción de poder votar si aprueban o no el texto propuesto. Por el contrario, salvo en el citado caso de Massachusetts, la regulación de la iniciativa de enmienda constitucional establecida en diversos estados no permite al legislativo bloquear o modificar la voluntad de los impulsores de la iniciativa de reforma constitucional y ésta debe ser sometida a la directa consideración de la ciudadanía.

Una de las funcionalidades de la iniciativa popular de enmienda constitucional es permitir a los ciudadanos sortear una sentencia que declara la inconstitucionalidad de una ley. Así pasó, por ejemplo, en In re Marriage Cases, donde el Tribunal Supremo de California declaró en 2009 inconstitucional una iniciativa legislativa popular, ratificada mediante referéndum, que limitaba el matrimonio a la unión entre un hombre y una mujer. Los ciudadanos promovieron entonces una iniciativa popular de enmienda constitucional que prohibiera el matrimonio entre personas del mismo sexo. El Tribunal Supremo de California, en su sentencia Strauss v. Horton, de 26 de mayo de 2009, consideró que dicha iniciativa popular de enmienda constitucional, ratificada democráticamente, no podía ser declarada inconstitucional. En este caso, al tratarse de una enmienda constitucional y no de una ley, la única posibilidad de que se declarara inconstitucional era por motivos procedimentales, lo que los demandantes intentaron señalando que se había producido una revisión constitucional y no una mera enmienda, tesis que no fue aceptada por el Tribunal por considerar que el matrimonio entre personas del mismo sexo no era un aspecto nuclear del texto constitucional. Finalmente, años después, en el célebre caso Obergefell v. Hodges, decidido por el Tribunal Supremo federal en junio de 2015, terminó declarándose que el derecho a contraer matrimonio se garantiza también a las personas del mismo sexo de acuerdo con la cláusula sobre protección igualitaria establecida en la decimocuarta enmienda de la Constitución federal ${ }^{33}$.

Veamos entonces en detalle cómo está regulada la iniciativa popular de enmienda constitucional en aquellos estados que han establecido el mecanismo.

33 El Tribunal Supremo federal durante las tres primeras décadas de nacimiento de las iniciativas de enmienda constitucional llevó a cabo un estricto control de las medidas de intervención económico de signo progresista que se estaban produciendo por aquel entonces, lo que limitó en gran medida sus posibilidades. Ese momento de activismo judicial en clave conservadora tuvo su inicio en 1905 con el caso Lochner v. New York. En el mismo, el Tribunal Supremo federal declaró inconstitucional una ley del estado de Nueva York que tenía por objeto limitar a sesenta horas las horas de trabajo semanales de los panaderos. La mayoría del Tribunal Supremo terminó defendiendo que la ley violaba la libertad de contrato establecida, implícitamente, en la sección primera de la decimocuarta enmienda cuando señala que ningún estado podrá privar a una persona de su libertad individual. Desde su punto de vista, la libertad contractual, la posibilidad de «limitar las horas en que los hombres adultos e inteligentes pueden trabajar para ganarse la vida» y de que "patrones y trabajadores pacten sus horarios de trabajo como mejor les convenga», únicamente podría limitarse en caso de que tuviera como causa la protección de la salud pública o la salud de los trabajadores. En este caso particular se argumentó que la profesión de panadero no es insalubre y no presenta más que otras profesiones un riesgo para la salud de los empleados. El breve voto disidente del juez Holmes es célebre por su denuncia del enmascaramiento de una posición ideológica determinada bajo un aparente tecnicismo. 
En primer lugar, debe procederse al registro y aprobación de circulación de la iniciativa por parte de un número variable de ciudadanos ${ }^{34}$. La petición de registro de la iniciativa, cuya forma predeterminada se suele indicar por ley ${ }^{35}$, se hace ante un cargo público, que suele ser el secretario de estado o el fiscal general. Los poderes del cargo público encargado de recibir la iniciativa varían en los diferentes estados. En algunos casos está capacitado para rechazar una propuesta por entender que es contraria al texto constitucional o a la legalidad vigente ${ }^{36}$. En otros, sin embargo, ésta únicamente capacitado para sugerir la corrección de los errores que pueda observar, debiendo encargarse los tribunales del eventual rechazo de registro de la iniciativa ${ }^{37}$. Asimismo, recibida la petición, debe confirmar su recepción y publicitarse la misma. En algunos estados ello permite a algunos ciudadanos intervenir desde ese momento en el proceso para plantear objeciones a la iniciativa e impedir así que se proceda a la fase de recogida de firmas ${ }^{38}$.

En cuanto a la no contradicción de la iniciativa al ordenamiento deben hacerse diversas observaciones. La primera, de carácter general, es que no se puede proceder al registro de una iniciativa que contravenga el ordenamiento federal, incite a la violencia, sea discriminatoria, arbitraria y que contravenga la distribución territorial de competencias ${ }^{39}$. La segunda, de carácter particular, radica en los límites formales y materiales que algunos estados establecen a las iniciativas populares de reforma constitucional. Por lo que respecta a los límites formales, es común en muchos estados la llamada single-subject rule, igualmente aplicable a las enmiendas

34 En Dakota del Norte, se debe presentar una solicitud de aprobación con los nombres y firmas de veinticinco o más electores como promotores, uno de los cuales debe designarse como presidente del comité promotor (véase la Constitución de Dakota del Norte, artículo III, sección 2). Oregón es uno de los estados que requiere que la petición de registro de la iniciativa vaya acompañada de un número de firmas. En concreto, los peticionarios deben presentar al secretario de estado las firmas de 1000 votantes. Antes de proceder a la recogida de dichas firmas, los peticionarios deben presentar al secretario de estado una declaración en la que señalarán si los recolectores de firmas recibirán dinero para realizar su tarea (véanse las Leyes del estado de Oregón, volumen 6, sección 23, capítulo 250.045).

35 Véase, a modo de ejemplo, las Leyes de Oklahoma, título 34, párrafo 2.

36 En Massachusetts, el fiscal general debe revisar la propuesta para asegurarse de que no incumple los límites materiales establecidos en la Constitución (Constitución de Massachusetts, artículo LXXIV, sección 1). En Arkansas, los proponentes de la iniciativa deben enviar un borrador de título y resumen de la misma. El fiscal general tendrá diez días para dar respuesta a la propuesta, pudiendo realizar modificaciones a la misma. Asimismo, si considera que el planteamiento puede inducir al engaño, puede rechazarlo y pedir a los proponentes que lo rediseñen. En caso de que los proponentes no estén de acuerdo con la medida adoptada, pueden presentar un recurso ante el Tribunal Supremo estatal (Código de Leyes de Arkansas, título 7, capítulo 9, subcapítulo 107).

37 En el caso de Florida, el fiscal general tiene la obligación de remitir la propuesta al TS del estado para que compruebe su validez (Constitución de Florida, artículo IV, sección 10).

38 En Oklahoma, el secretario de estado debe hacer pública en al menos un periódico de ámbito general la propuesta de iniciativa. En el mismo aviso debe indicar que cualquier ciudadano puede presentar una protesta acerca del título presentado o la constitucionalidad de la petición de iniciativa ante el Tribunal Supremo estatal durante los diez siguientes días a su publicación (Leyes de Oklahoma, título 34, párrafo 8).

39 Tymкovich, T.M., «Are State Constitutions Constitutional?», Minnesota Law Review, vol. 97, n. ${ }^{\circ}$, 2017, p. 1813. 
impulsadas por el legislativo. Con la finalidad de promover que los ciudadanos puedan tomar una decisión informada y evitar que la pregunta induzca a engaño o confusión, se prohíbe que las proposiciones de enmienda constitucional puedan contener más de una cuestión ${ }^{40}$. De esa forma, se evita que se combine en una misma pregunta una propuesta popular con otra no directamente relacionada obligando así a los votantes a tomarlo todo o dejarlo ${ }^{41}$. Los tribunales se han enfrentado en numerosas ocasiones a casos relativos al incumplimiento de dicha regla. En directa relación con ello, y con el objeto de mejorar la calidad del debate público, algunos estados limitan también el número de enmiendas que se pueden presentar en cada elección, trasladando aquellas propuestas de enmienda que por dicha limitación no puedan plantearse a la próxima elección general ${ }^{42}$. Asimismo, para impedir que en cada elección general se debata sobre las mismas cuestiones, algunas constituciones restringen temporalmente el planteamiento de enmiendas similares ${ }^{43}$. Vermont va incluso más allá delimitando el momento de planteamiento de enmiendas a una ocasión cada cuatro años ${ }^{44}$.

Por lo que respecta a los límites materiales a las iniciativas populares de enmienda constitucional, son dos los grandes pilares que se han regulado: la asignación directa de fondos ${ }^{45}$ y la protección de determinadas disposiciones

40 Véase, por ejemplo, la Constitución de Arizona, artículo XXI, sección 1 o la Constitución de Colorado, artículo XIX, sección 3. La Constitución de Oregón prevé en su artículo XVII, sección 2, la posibilidad de que una enmienda constitucional planteada por el legislativo coincida con la misma temática que otra impulsada mediante iniciativa popular. En ese caso la pregunta deberá contener los dos textos alternativos.

41 Kafker, S.L., Russcol, D.A., «The Eye of a Constitutional Storm: Pre-Election Review by the State Judiciary of Initiative Amendments to State Constitutions», Michigan State Law Review, vol. 2012, n. ${ }^{\circ}$, p. 1306.

42 Illinois y Arkansas limitan el número máximo de artículos constitucionales susceptibles de enmiendas a tres. Véase el artículo XIV, sección 2 de la Constitución de Illinois y el artículo 19, sección 21 de la Constitución de Arkansas. Por su parte, Kentucky establece una limitación de 4 propuestas de enmienda (Constitución de Kentucky, sección 256) y Kansas de 5 (Constitución de Kansas, artículo XIX, sección 1).

43 En el caso de Nueva Jersey, si una enmienda no es aprobada, no podrá volver a someterse a la consideración de los ciudadanos una cuestión similar hasta pasadas tres elecciones generales estatales (Constitución de Nueva Jersey, artículo IX). Por su parte, en Pensilvania se establece una restricción de cinco años (Constitución de Pensilvania, artículo XI, sección 1).

44 Constitución de Vermont, sección 72. Esta provisión se reformó en 1974. Anteriormente, el plazo para plantear enmiendas era de 10 años. Al respecto de la reducción del time-lock en Vermont, véase BRYAN, F., «Reducing the Time-Lock in the Vermont Constitution: An Analysis of the 1974 Referendum», Vermont History, vol. 44, n. ${ }^{\circ} 1,1976$, pp. 38-47.

45 La Constitución de Massachusetts en su artículo XLVIII lo prohíbe expresamente. Como posibilidad alternativa, la Constitución de Arizona en su artículo IX, sección 23, determina que una iniciativa que proponga un gasto obligatorio de ingresos estatales «debe proporcionar una fuente de ingresos mayor que cubra todos los costos inmediatos y futuros de la propuesta. El aumento de los ingresos no puede derivarse del fondo general del estado ni reducir o causar una reducción en los ingresos del fondo general». La experiencia californiana demostraría aparentemente las contradicciones inherentes al modelo de no limitación en la asignación de fondos públicos mediante iniciativas populares de enmienda constitucional. Los votantes de California han aprobado en las últimas décadas diferentes iniciativas cuyo objetivo era limitar el margen de maniobra del legislativo en materia de gasto público y fiscal. Véase Moreno GonzÁlez, G., «Más allá de la regla de oro: Las otras restricciones constitucionales al poder fiscal y presupuestario», Revista Española de Derecho Constitucional, n. ${ }^{\circ}$ 115, 2019, pp. 205-227. No obstante, también se han 
constitucionales consideradas merecedoras de una mayor protección ${ }^{46}$. En ambos casos, tal y como ha sido expresado por los propios defensores de estas limitaciones, no se considera confiables a las mayorías para poder plantear enmiendas constitucionales sobre determinadas cuestiones ${ }^{47}$. Ahora bien, estas limitaciones de carácter material, si bien reseñables, son minoritarias en el conjunto de regulaciones estatales.

Una vez aceptado el registro de la iniciativa, se debe proceder a redactar el título y el resumen de la iniciativa que se publicitará durante la recogida de

aprobado iniciativas que han impuesto un suelo de gasto en diferentes áreas consideradas esenciales tales como educación y protección medioambiental. De esa forma, a pesar de haberse constitucionalizado la estabilidad presupuestaria, en caso de necesidad pueden mandatarse gastos por encima de los ingresos. Véase Cain, Noll, «Malleable Constitutions: Reflections on State Constitutional Reform», p. 1543. Esta contradicción entre políticas económicas procedentes ambas de iniciativas populares, se salvó en parte gracias a otra iniciativa popular de enmienda constitucional, la proposición 30 de 2012, gracias a la cual, por primera vez en dos décadas, los votantes californianos aprobaron un notable aumento de impuestos dirigido especialmente a las rentas altas para así poder aumentar el gasto público social. De esta forma, independientemente de las consideraciones que se puedan realizar en materia de política económica, la iniciativa de enmienda constitucional ha permitido a los votantes californianos intervenir en aspectos esenciales e ir adaptando sus preferencias a lo largo del tiempo a través del ensayo-error. De hecho, la experiencia de estados como el de California fue sin duda clave para el rechazo de los votantes de Dakota del Norte a una propuesta de enmienda constitucional impulsada por el legislativo en 2014 dirigida precisamente a impedir la asignación de fondos públicos derivadas de iniciativas populares de enmienda constitucional. Como lo resumió un ex vicegobernador del estado, «al proponer la medida 4, el legislativo le está diciendo a los ciudadanos de Dakota del Norte que no se les puede confiar la gestión de fondos públicos. Muchos ciudadanos tienen la misma desconfianza hacia los legisladores. De ahí que tengamos disposiciones constitucionales que establecen la iniciativa y el referéndum». Véase OMDAHL, L., «Legislature questions intelligence of the voters», The Jamestown Sun, 2014.

46 El caso más citado por la literatura es el de Massachusetts. En el artículo 48 de la Constitución del Old Bay State se establece que no podrán ser susceptibles de iniciativa popular una larga lista de materias, entre las cuales, medidas relacionadas con las prácticas e instituciones religiosas o aquellas contradictorias con determinados derechos del individuo como la libertad de expresión, voto, reunión y prensa o a la compensación por expropiación. En sentido similar, el artículo 15, sección 273 de la Constitución de Mississippi, imposibilita el uso de la iniciativa de enmienda constitucional para, entre otras cuestiones, reformar la carta de derechos estatal. El TS del estado defendió la introducción de este tipo de límites señalando en Elizabeth Stoner v. Robert Maboney que tienen por objeto «atenuar la tensión inducida por la iniciativa entre la voluntad incontrolada de la mayoría y los derechos inherentes de los individuos». La relación del TS de Mississippi con la iniciativa popular ha sido especialmente tormentosa. En 1914, los votantes del Magnolia State ratificaron una propuesta de enmienda constitucional de acuerdo con la cual se introducía la iniciativa legislativa y de enmienda constitucional en la Constitución. No obstante, en 1922, en Power $v$. Robertson, el TS del estado declaró nula la enmienda por entender que había violado la single-subject rule al haberse preguntado sobre dos cuestiones que requerían de dos referéndums diferentes. Mississippi se convirtió entonces en el único estado que habiendo introducido una iniciativa popular estatal la terminó retirando. No siendo, además, esta decisión voluntad de los votantes. No fue hasta 1992 cuando los ciudadanos residentes en Mississippi tuvieron opción de volver a ratificar una enmienda constitucional de acuerdo con la cual se establecía la iniciativa de enmienda constitucional. Para un breve repaso a la historia de la iniciativa popular en Mississippi, véase $\mathrm{SCH}-$ MIDT, D.D., Citizens Lawmakers: The Ballot Initiative Revolution. Philadelphia: Temple University Press, 1989, p. 245. La Constitución de Illinois, por su parte, en su artículo XIV, sección 3, circunscribe la iniciativa de enmienda constitucional al artículo IV de la Constitución, relativo a la elección, composición y funciones del legislativo.

47 Kafker, Russcol, «The Eye of a Constitutional Storm: Pre-Election Review by the State Judiciary of Initiative Amendments to State Constitutions», p. 1310. 
firmas y se incorporará a la papeleta de voto. Esta fase, que aparentemente podría revestir una importancia menor, suscita numerosas controversias. Con el fin de evitar un trato sesgado y transmitir con la mayor objetividad posible la voluntad de los proponentes de la iniciativa, el encargado de proceder a la redacción del título y el resumen es en la práctica totalidad de los casos un cargo público ${ }^{48}$. Éste puede tener que proceder a su redacción en un periodo escaso de tiempo y siguiendo unas pautas estrictas por lo que respecta al número de palabras que debe contener el título y el resumen ${ }^{49}$. Los proponentes de la iniciativa juegan un papel variable dependiendo del estado. En algunos de ellos pueden llegar a escribir el primer borrador y, en caso de que la redacción final que plantee el cargo público no les satisfaga, demandar una nueva versión. En otros, por el contrario, los ciudadanos no juegan ningún papel, teniendo únicamente capacidad de acción ante los tribunales.

Así, ante los posibles desacuerdos que puedan surgir, la mayoría de estados establecen la posibilidad de que cualquier ciudadano interesado o los patrocinadores de la iniciativa acudan a los tribunales para que éste dé respuesta a sus pretensiones en un procedimiento preferente y acelerado ${ }^{50}$. El Tribunal, a su vez, puede actuar diferentemente dependiendo del estado. En caso de que consideren que la redacción es incorrecta, en algunos casos tienen potestad para plantear una nueva $^{51}$, lo que ha generado no pocas polémicas ${ }^{52}$. En otros, sin embargo, se establece una regulación más restrictiva obligando al Tribunal a reenviar al escritor del título y el resumen para que proceda a su reescritura ${ }^{53}$.

48 En Dakota del Norte, por ejemplo, se encarga de dicha tarea al secretario de estado (Código de Leyes de Dakota del Norte, título 16.1, capítulo 16.1-01-01). Otros estados han optado por el fiscal general (Leyes de Oregón, volumen 6, sección 23, capítulo 260.065),

49 En Oregón, una vez el fiscal general recibe la propuesta de iniciativa, dispone de 5 días para redactar título y resumen (Leyes de Oregón, volumen 6, sección 23, capítulo 260.065).

50 El Código de Leyes de Mississippi, título 23, capítulo 17, párrafo 13, legitima a cualquier ciudadano para que, durante los cinco siguientes días a la publicación por parte del secretario de estado del título y el resumen de la iniciativa, realice el oportuno recurso ante determinado tribunal de primera instancia. El tribunal otorgará prioridad al examen de la medida propuesta y emitirá su decisión dentro de diez días. En Dakota del Norte, como en la mayoría de estados, el ciudadano deberá acudir al Tribunal Supremo estatal (Constitución de Dakota del Norte, artículo III, sección 7).

51 Cfr. Leyes de Nebraska, capítulo 32, sección 1410.

52 Véase al respecto el caso de Oregón, donde durante la década de los 90 del siglo pasado el TS de Oregón se vio envuelto en numerosos casos de petición de reescritura de títulos, lo que terminó haciendo en no pocas ocasiones. Para un análisis al respecto véase LUND, W.A., «What's in a Name? The Battle over Ballot Titles in Oregon», Willamette Law Review, vol. 34, 1998, pp. 143-168.

53 Esto suele ocurrir en aquellos estados en los que no hay desarrollo legal al respecto. Así, por ejemplo, en Lungren v. Superior Court, resuelto en 1996 por un Tribunal de apelación de California, invalidó la sentencia del Tribunal de primera instancia relativa a una disputa en torno al título de una propuesta de enmienda constitucional relativa a la prohibición de la discriminación positiva en las instituciones públicas. El Tribunal de primera instancia consideró que el título era ilegal puesto que inducía a engaño, incumpliendo así lo dispuesto en el Código Electoral de California. De esa forma, requirió al fiscal general que volviera a escribir el título. No obstante, el Tribunal de apelación, después de realizar un detallado análisis del título, terminó dando la razón al fiscal general. 
Antes de proceder a la fase de recolección de firmas, algunos estados también obligan a que se redacte un informe financiero sobre el impacto que va a tener la iniciativa propuesta en la hacienda pública ${ }^{54}$. El objeto del mismo, es claro, es que los ciudadanos pueden tener un mayor conocimiento de causa sobre el impacto económico de la iniciativa. En no pocas ocasiones, una iniciativa requiere de un aumento de impuestos o de una reestructuración de los presupuestos, por lo que se considera conveniente que los ciudadanos dispongan de esa información antes de votar. Algunos estados obligan además a que se incluya un breve resumen del impacto fiscal en la papeleta de voto junto al título y resumen de la iniciativa para cerciorarse que al menos sus líneas básicas son conocidas por los votantes ${ }^{55}$.

Superados todos los trámites anteriores, puede procederse a la fase de recolección de firmas. Al margen de otras cuestiones relativas a la negación de derecho de voto a los ciudadanos que hayan cumplido condenas de cárcel por delitos graves o de las dificultades crecientes que se están dando en algunos estados para registrarse como votante, no plantea problemas el hecho de que la iniciativa la pueden firmar todos los ciudadanos registrados como votantes en el estado. Sí los plantea, en cambio, quién puede recoger las firmas y de qué forma lo pueden hacer. Por lo que respecta a la primera cuestión, el problema radica en la posibilidad de retribuir a los recolectores de firmas. Esta tendencia, creciente desde los años setenta, ha llevado a algunos investigadores a señalar que se estaba dejando la puerta abierta de par en par a la desfiguración de los objetivos del instituto de participación directa mediante la injerencia directa de poderosos grupos de interés $^{56}$. En cualquier caso, la constatación que la influencia del dinero ejerce sobre el procedimiento ha llevado a algunos estados a regular la cuestión obligando a hacer público el nombre de los financiadores de la iniciativa ${ }^{57}$ o limitando la retribución a los recolectores de firmas ${ }^{58}$.

54 La Constitución de Dakota del Norte en su artículo III, sección 2, obliga a que el consejo legislativo, el órgano de apoyo técnico legislativo al legislativo, redacte un informe del impacto fiscal de toda iniciativa propuesta. Dicho informe, establece también la Constitución, debe hacerse público.

55 Cfr. Código Electoral de California, párrafo 303.5.

56 No obstante, el estudio más citado y completo al respecto concluye que ha de matizarse en gran medida dicha injerencia y que no hay datos concluyentes que correlacionen la aprobación de una medida impulsada por dichos grupos de presión. Véase Gerber, E.R., The Populist Paradox. Princeton: Princeton University Press, 2011. En cualquier caso, es remarcable la importante «industria» que existe detrás de las iniciativas populares. Desde hace décadas existen bufetes de abogados, consultores políticos y empresas de recogida de firmas especializadas en impulsar iniciativas populares. Los primeros ayudan a sus clientes a redactar el texto de la iniciativa y la defienden en los tribunales tanto antes como después de la votación en caso de que se presente un litigio. Los segundos ofrecen servicios de encuestas, microtargeting y relaciones con los medios. Los terceros, por su parte, se encargan de recoger las firmas requeridas, ofreciendo un precio variable por cada una de ellas. Véase al respecto Ellis, R.J., «Signature Gathering in the Initiative Process: How Democratic Is It?», Montana Law Review, vol. 64, 2003, pp. 35-97.

57 Cfr. Código Electoral de California, división 9, artículo 7.

$58 \mathrm{El}$ pago a los recolectores de firmas es tan antiguo como la propia iniciativa en sí misma. En ese sentido, los estados no tardaron en prohibirlo por entender que con ello se desvirtuaba la esencia de la iniciativa popular. Ohio, Dakota del Sur y Washington lo hicieron en 1913 y 1914. Hasta principios de la década de los ochenta, 
Por lo que respecta a la forma de recolección de firmas, en todos los estados se establece que ésta deberá llevarse a cabo mediante firma en persona, debiendo tener la hoja de firma el título y el resumen de la iniciativa y la declaración jurada en cada una de ellas por parte del recolector de que todo firmante lo ha hecho estando él presente $^{59}$. El firmante, al margen de sus datos personales, debe indicar en algunos casos su dirección de residencia ${ }^{60}$. En los últimos años se ha empezado a discutir la posibilidad, al estilo de la Iniciativa Ciudadana Europea, de que se pueda proceder a firmar en línea a través de un portal de Internet ${ }^{61}$. La crisis derivada de la pandemia del Coronavirus ha creado las condiciones para esta posible transición. Así, por ejemplo, el Gobernador de Colorado decretó que, durante un mes, los electores registrados pudieran firmar por correo y correo electrónico iniciativas populares ${ }^{62}$.

El número total de firmas que se requiere para que la iniciativa sea finalmente sometida al escrutinio público tiene una particularidad común en todos los estados: se calcula por porcentaje y no por un número prefijado de firmas, como en el caso de las antes mencionada Iniciativa Ciudadana Europea. Ello, sin duda, resulta más beneficioso puesto que permite tener en cuenta las variaciones de población. Por lo demás, los diferentes estados regulan la cuestión diferentemente en dos sentidos. Por un lado, al margen de las variaciones en el porcentaje total de firmas requerido, algunos estados toman como punto de referencia la población total de estado ${ }^{63}$ o de votantes registrados ${ }^{64}$, mientras que otros requie-

dicha prohibición no fue declarada inconstitucional por ningún tribunal federal o estatal. El punto de inflexión se produjo en 1988 en Meyer v. Grant, cuando el Tribunal Supremo federal argumentó que la prohibición que había establecido el estado de Colorado de acuerdo con la cual se consideraba delito el pago violaba el derecho a la libertad de expresión. Esta sentencia ha servido de base para que se declararan inconstitucionales otras leyes en diferentes estados y ha disminuido en gran medida el margen de maniobra para evitar dichas prácticas. No obstante, algunos estados incluyen todavía una restricción importante al pago por la recogida de firmas, con el importante matiz que de únicamente se prohíbe el pago por número de firmas recogidas, no impidiéndose que se pague únicamente por recoger firmas. Así, por ejemplo, los votantes de Oregón aprobaron una iniciativa de enmienda constitucional en 2002 para introducir una prohibición de esas características (véase la Constitución de Oregón, artículo IV, sección 1b). El Tribunal federal de Apelación del Noveno Circuito defendió la adecuación de la medida a la Constitución federal en 2006 en Prete v. Bradbury. El Tribunal, recordando que la primera enmienda no prohíbe cualquier tipo de restricción sobre los procesos electorales, señaló que el objeto de evitar el pago por firma era evitar el fraude en su recolección y que el pago por hora trabajada permitía que los peticionarios pudieran igualmente recolectar el número requerido de firmas. En un mismo sentido, véase Initiative Referendum Inst. $v$. Jaeger y Person $v$. New York State Bd. of Elections resueltos también por tribunales de apelaciones federales al respecto de regulaciones legislativas análogas en Dakota del Norte y Nueva York, respectivamente.

59 Cfr. Código Electoral de California, divisón 9, capítulo 1, artículo 2, párrafo 9022.

60 Cfr. Código Electoral de California, división 9, capítulo 1, artículo 2, párrafo 9020.

61 En el momento en que se escribe este artículo está en proceso de debate el proyecto de ley 2021 de Arizona. De acuerdo con éste, el secretario de estado deberá establecer un sistema para que los votantes puedan firmar una petición de iniciativa o referéndum a través de un portal de internet.

62 State of Colorado Executive Order D 2020 065. Puede consultarse en línea en: https://www. law360.com/articles/1274456/attachments/0

63 Dakota del Norte requiere un $4 \%$ de la población del estado (artículo III, sección 9 de la Constitución de Dakota del Norte).

64 Nebraska establece un 10\% de los votantes registrados (artículo III, sección 2 de la Constitución de Nebraska). 
ren un porcentaje de votos de las últimas elecciones a gobernador ${ }^{65}$, secretario de estado $^{66}$ o presidente ${ }^{67}$. Por otro lado, existen variaciones en la forma de contabilizar los votos. Algunos estados exigen que un determinado número de divisiones administrativas lo aprueben con un porcentaje determinado ${ }^{68}$.

Por último, como no podía ser de otra forma, los estados también establecen regulaciones diversas por lo que respecta al tiempo máximo que se permite para la recolección de firmas y para su entrega para que pueda ser tomada en consideración y entrar en la siguiente elección. Por lo que respecta a la primera cuestión, el abanico de posibilidades oscila entre el tiempo ilimitado de Oregón ${ }^{69}$ o los dos años de Florida ${ }^{70}$ y los noventa días de Oklahoma ${ }^{71}$. No obstante, la mayoría de estados dan un año como tiempo máximo para la recogida de firmas ${ }^{72}$.

Recogido el número de firmas requerido se inicia el periodo de campaña electoral, en el que publicita la propuesta de enmienda y se distribuyen materiales con los puntos de vista favorables y contrarios a la misma o acerca de su impacto fiscal ${ }^{73}$. Tras el periodo de información y campaña, se procede a someter a votación la propuesta de enmienda. Los porcentajes requeridos para la ratificación de la enmienda en los diferentes estados son igualmente variables. Por norma general, se requiere una mayoría de votantes ${ }^{74}$. No obstante, algunos estados

65 Son mayoría los estados que toman como punto de referencia las elecciones a gobernador. Así, por ejemplo, Oklahoma requiere un $15 \%$ de los votos en las últimas elecciones a gobernador (artículo IV, sección 2 de la Constitución de Oklahoma).

66 Colorado es el único estado que toma al secretario de estado como referencia, siendo un $5 \%$ de los votos en este caso (artículo V, sección 1 de la Constitución de Colorado).

67 Florida es el único estado que toma al presidente como referencia, siendo un $8 \%$ de los votos en este caso (artículo IX, sección 3 de la Constitución de Florida).

68 El artículo III, sección 2 de la Constitución de Nebraska requiere que del10\% de los votantes registrados, un $5 \%$ firmen en dos quintos de los condados.

69 Oregón no establece límite alguno ni en su Constitución (artículo IV, sección 1) ni en su Código de Leyes (capítulo 250, sección 45).

70 Código de Leyes de Florida, título IX, capítulo 100.371, sección 3. Hasta 2011 el periodo máximo en Florida era de cuatro años.

71 Código de Leyes de Oklahoma, título 34, sección 2.

72 Cfr. Código de Leyes de Montana, título 13, capítulo 27, sección 202.

73 El Código Electoral de California (división 9, artículo 7), por ejemplo, determina que el estado debe enviar por correo a los votantes y subir a Internet una guía de información al votante, que debe encargarse de preparar el secretario de estado. Dicha guía, traducida a varios idiomas y disponible en versión audio y en lenguaje de signos, incluye, a su vez, una guía de referencia breve de cada una de las propuestas. Esta contiene un breve resumen de la propuesta, una explicación del significado del voto, argumentos a favor y en contra de las diferentes propuestas y el contacto de dos ciudadanos, uno favorable y otro contrario a la propuesta, para ulterior información. A continuación, se detallan en mayor medida las diferentes propuestas incluyendo también un análisis con los efectos fiscales, argumentos más extensos a favor y en contra y refutaciones de dichos argumentos. Asimismo, se señala la dirección web a la que acceder para conocer el total de contribuciones a favor y en contra de las medidas y de los diez principales contribuyentes. Véase, a modo de ejemplo, la proposición 3 de las elecciones de noviembre de 2018. Se trata de una iniciativa legislativa popular en la que se plantea a los votantes la venta de 8.9 mil millones de dólares en bonos de obligación general para financiar diversos proyectos hídricos y ambientales. Disponible en línea en: https://vig.cdn.sos.ca.gov/2018/general/pdf/complete-vig.pdf

74 Cfr. Constitución de Arizona, artículo XXI, sección 1. 
establecen requisitos agravados para su aprobación, ya sea una mayoría superior a la simple ${ }^{75}$, un determinado quórum ${ }^{76}$ o que la enmienda se apruebe en dos elecciones consecutivas ${ }^{77}$.

\section{EL PROCEDIMIENTO DE ENMIENDA CONSTITUCIONAL MEDIANTE UNA COMISIÓN AUTOMÁTICAMENTE CREADA EN FORMA PERIÓDICA: EL CASO DE FLORIDA}

La Constitución vigente de Florida estableció en el momento de su ratificación, en noviembre de 1968, en su artículo XI sección 2, un mecanismo único en todo EEUU. De acuerdo con el mismo, cada veinte años, con la excepción del primer mandato que tenía que tener lugar diez años después de la entrada en vigor de la Constitución, debe convocarse una comisión, la Comisión de Revisión de la Constitución de Florida (Florida Constitution Revision Commission), con potestad

75 En el caso de Florida, las enmiendas constitucionales propuestas requieren, como está establecido en el Artículo XI Sección 5(e) de la Constitución, un sesenta por ciento de votos afirmativos entre los votantes. Este requerimiento de una mayoría agravada es consecuencia, a su vez, de una enmienda constitucional planteada por el legislativo en noviembre de 2006, señalando la anterior regulación que el porcentaje de aprobación requerido era de la mitad más uno de los votantes. Paradójicamente, la enmienda entró en vigor con la aquiescencia de un porcentaje menor de votos al sesenta por ciento, el cincuenta y siete de los votantes. Para evitar una situación de este tipo, la Constitución de Oregón establece como excepción que las enmiendas que tengan por objeto ampliar la mayoría requerida para la ratificación de una iniciativa deban ser al menos aprobadas por la nueva mayoría propuesta (Constitución de Oregón, artículo II, sección 23). Dicho requisito fue establecido en Oregón como consecuencia de una iniciativa popular de enmienda constitucional ratificada en noviembre de 1998.

76 Nebraska requiere, además de la mayoría de los votos favorables sobre la propuesta, que el número de votos sobre la misma sea al menos igual al treinta y cinco por ciento de los máximos votos totales emitidos en el conjunto del proceso electoral (Constitución de Nebraska, artículo III, sección 4). Aunque se trata de un referéndum para llamar a elecciones a una convención constitucional, la Constitución de Maryland en su artículo XIV, sección 2, también establece el requisito de la doble mayoría, de acuerdo con el cual no sólo debe haber mayoría de votantes a favor de la pregunta del referéndum sino que el número de votantes que respaldan la pregunta debe ser igual o superior a la mitad más uno de los votantes en cualquier otra de las preguntas o elecciones que se celebren ese mismo día. Por ello, en los referéndums de convocatoria de una convención constitucional en dicho estado de 1930, 1950 y 2010, a pesar de que una mayoría de los votantes se expresó favorablemente, dicha mayoría no fue superior a la mitad más uno de los participantes en la votación que tuvo más participación en esa jornada electoral. De esa forma, no se pudo dar inicio, lógicamente, al proceso. En septiembre de 1966 tuvo lugar un referéndum extraordinario sobre si debía procederse a convocar elecciones a convención constitucional un año más tarde. El resultado de dicho referéndum, a pesar de la baja participación, en torno a un $14 \%$ de los votantes registrados, fue mayoritariamente positivo. En consecuencia, el Tribunal de Apelaciones de Maryland determinó en 1967 en Board of Supervisors of Elections v. Attorney General, el mandato popular de llamada a una convención constitucional no podía aquí obviarse pues no existía otra votación con la que comparar el número de votantes. Véase al respecto Wheeler, J.P., «Constitutional Reform Fails In The Free State: The Maryland Constitutional Convention Of 1967-68», Washington and Lee Law Review, vol. 26, n. ${ }^{\circ}$ 2, 1969, p. 225; Martineau, R.J., «Maryland's 1967-68 Constitutional Convention: Some Lessons for Reformers», Iowa Law Review, vol. 55, 1970, p. 1204.; Friedman, D., «Magnificent Failure Revisited: Modern Maryland Constitutional Law from 1967 to 1998», Maryland Law Review, vol. 58, 1999, p. 529.

77 Constitución de Nevada, artículo XIX, sección 2. 
para proponer directamente a la ciudadanía, sin contar con la aprobación del legislativo, enmiendas o revisiones constitucionales ${ }^{78}$. La Comisión está compuesta por treinta y siete miembros: el fiscal general, quince miembros electos por el Gobernador, de entre los cuales uno de ellos habrá de ejercer de presidente de la comisión, nueve miembros designados por el presidente de la Cámara de Representantes, nueve miembros electos por el presidente del Senado y tres miembros electos por el presidente de la Corte Suprema. Por lo que respecta a su organización interna, la Comisión se dota de sus propias reglas de procedimiento ${ }^{79} \mathrm{y}$, por lo tanto, decide su forma de organización. Está organizada en diferentes comités temáticos relacionados con diferentes aspectos de la Constitución que cuentan con el apoyo de un comité centrado en las reglas de procedimiento y la administración de la Comisión y un comité de redacción que tiene por objetivos aclarar, codificar y organizar las propuestas adoptadas por la Comisión y preparar el informe final de la Comisión. Asimismo, tiene la obligación de llevar a cabo audiencias públicas y, en el caso de que considere plantear enmiendas a la Constitución del estado, debe hacerlo ciento ochenta días antes de la celebración de las elecciones generales.

La ciudadanía no sólo tiene la potestad para decidir si acepta o no las enmiendas constitucionales que propone la Comisión, sino que juega un papel activo durante los trabajos de la misma. Durante las audiencias públicas que debe realizar la Comisión, los asistentes pueden realizar propuestas para que sean tomadas en cuenta por la Comisión. Así, por ejemplo, con ocasión de las elecciones de noviembre de 2018 , como se puede comprobar en su página web ${ }^{80}$, la Comisión convocó quince audiencias públicas en diferentes municipios del estado. Los nombres, dirección, teléfono, correo electrónico de todos los asistentes y todos los documentos recibidos se hicieron públicos. Asimismo, se transcribió el contenido de las reuniones íntegramente para que pueda procederse a su consulta. Los ciudadanos, además, pudieron enviar sus propuestas a través de la página web y mediante correo ordinario y electrónico. Todas las propuestas recibidas, así como

78 De acuerdo con el artículo constitucional que regula la Comisión, aunque ésta también estaría capacitada para proponer propuestas de revisión constitucional, hasta el momento únicamente ha planteado enmiendas constitucionales.

79 Véase «Rules of the Constitutional Revision Commission 2017-2018». Disponible en línea en: http://www.flcrc.gov/PublishedContent/ADMINISTRATIVEPUBLICATIONS/Rules.pdf

Respecto a la facultad de la Comisión para dotarse de sus propias reglas de procedimiento, se estableció tempranamente la facultad para que ésta pudiera hacerlo en un dictamen consultivo de la Corte Suprema de Florida solicitado por el gobernador. Dicho punto de vista fue además reforzado por un dictamen del fiscal general del estado en la que señaló que la ley de procedimiento administrativo estatal no se aplicaba a la Comisión. El objetivo era reforzar la independencia del órgano frente a las otras ramas del poder, aunque, como hemos visto, está formado por todas las ramas del poder. Véase MAE SALOKAR, R., "Constitutional revision in Florida: planning, politics, policy, and publicity». En Williams, R.F., TARR, A.G. eds. State Constitutions for the Twenty-first Century, Volume 1: The Politics of State Constitutional Reform. Albany: State University of New York Press, 2006, p. 35.

80 Véase: http://www.flcrc.gov/Meetings/PublicHearings.html 
el nombre del que la realiza, pueden consultarse en línea. De acuerdo con los datos disponibles, se recibieron 782 propuestas a través de la página web y 1231 a través de las otras vías ${ }^{81}$. La Comisión, de esa forma, pudo medir el interés que suscitaba cada propuesta para proceder a su toma en consideración ${ }^{82}$.

Las facultades de la Comisión causaron en un inicio importantes recelos en sede legislativa. En 1980 la mayoría legislativa impulsó una enmienda constitucional para suprimirla. No obstante, los electores votaron en contra de la misma, preservando así el instrumento ${ }^{83}$. Ahora bien, dado el método de elección de los comisionistas, como han puesto de relieve algunos autores que han puesto en entredicho la independencia de la Comisión ${ }^{84}$, dichos recelos no parecen justificados o pueden únicamente explicarse por la intervención del gobernador en el proceso. Tomando por ejemplo el caso de la Comisión de 2017-2018, todos los comisionistas, menos aquellos nombrados por el presidente de la Corte Suprema de Florida y la Fiscal General, fueron electos por miembros del Partido Republicano. A su vez, el presidente de la Corte Suprema fue electo por un gobernador del Partido Republicano, Jorge Labarga, y la fiscal general, Pam Bondi, fue electa como miembro del mismo partido. A pesar de la introducción de mecanismos de participación ciudadana y de rendición de cuentas, el método de elección de la Comisión hace dudar acerca de la posibilidad de que prosperen propuestas contrarias al programa político del partido que controle el legislativo y encabece el ejecutivo. En cualquier caso, como se viene insistiendo, la última palabra la siguen teniendo directamente los ciudadanos ${ }^{85}$.

Por otra parte, ha de señalarse que en Florida existe otro mecanismo único en todo el país que tiene entre sus atribuciones la de plantear enmiendas a la

81 Véase: http://www.flcrc.gov/PublishedContent/ADMINISTRATIVEPUBLICATIONS/CRCPublicProposals.pdf

82 De acuerdo con las reglas de procedimiento de la Comisión, en caso de que una propuesta reciba diez votos afirmativos, previa moción de un comisario, la Comisión deberá tomarla en consideración. Pudiendo ser analizada previamente por parte del comité temático relacionado con la propuesta, el Pleno de la Comisión puede enmendar la propuesta antes de pasar a ser considerada por el Comité de redacción, que a su vez puede plantear enmiendas para clarificar y codificar la propuesta o agruparla junto a otras propuestas. Por último, el Pleno de la Comisión debe decidir por mayoría de tres quintos si acepta las recomendaciones del Comité de redacción, considerar enmiendas adicionales y si la propuesta debe someterse a votación por la ciudadanía. Antes de esta última fase, la Comisión vuelve a realizar audiencias públicas para hacer públicas sus propuestas y obtener así retroalimentación por parte de la ciudadanía.

83 Williams, «The Law of American State Constitutions», p. 370.

84 CaIn, Noll, «Malleable Constitutions: Reflections on State Constitutional Reform», p. 1523.; BENJAMIN, G., «The Mandatory Constitutional Convention Question Referendum: The New York Experience in National Context». En Williams, R.F., Tarr, A.G. eds. State Constitutions for the Twenty-first Century, Volume 1: The Politics of State Constitutional Reform. Albany: State University of New York Press, 2006, p. 191.

85 De esta forma, los votantes de Florida han rechazado algunas de las propuestas que se les ha plantado desde la Comisión. En la primera serie de votaciones, 1977, la Comisión planteó ocho enmiendas a la Constitución y todas ellas fueron rechazadas. Veinte años más tarde, la experiencia fue más exitosa. De las nueve enmiendas que planteó la Comisión, ocho resultaron exitosas. En el proceso electoral de noviembre de 2018, se sometieron a consideración de los ciudadanos siete enmiendas a la Constitución provenientes de la Comisión, siendo todas ellas ratificadas. Entre otras cuestiones, se ratificó prohibir la perforación, ya sea para exploración o extracción, de petróleo o gas natural en aguas estatales. 
Constitución. La Comisión de reforma impositiva y presupuestaria (Taxation and budget reform commission), establecida mediante enmienda constitucional en el artículo XI Sección 6 tras ser ratificada por los votantes en noviembre de 1988 , debe también reunirse automáticamente cada veinte años, siendo la primera vez que lo hizo en 2007. Entre otros objetivos, la Comisión puede plantear enmiendas constitucionales en materia impositiva y presupuestaria. En forma similar a la Comisión de revisión constitucional, está compuesta por veinticinco miembros, de los cuales once son electos por el gobernador, siete son electos por el presidente de la Cámara de Representantes y otros siete por el presidente del Senado. Ninguno de ellos puede ser miembro del legislativo en el momento de su elección. Asimismo, se eligen otros cuatro miembros ex officio que deben ser miembros del legislativo. Dos de ellos deben ser electos por el presidente de la Cámara de Representantes, debiendo ser uno del partido en minoría en la cámara, y los otros dos deben ser electos por el presidente del Senado, debiendo, igualmente, ser uno del partido en minoría en la cámara. La Comisión de reforma impositiva y presupuestaria debe asimismo adoptar sus propias reglas de procedimiento ${ }^{86}$. Igualmente, del mismo modo que la Comisión de reforma constitucional, debe también llevar a cabo audiencias públicas a fin de recibir aportaciones de la ciudadanía.

Por último, ha de tenerse presente que en las últimas décadas viene siendo común que el legislativo o el ejecutivo de los diversos estados de la Unión creen una comisión constitucional, la cual puede o no estar compuesta por miembros del legislativo, para estudiar posibles reformas a la Constitución. Este mecanismo no suele estar regulado constitucionalmente ${ }^{87}$, pero ha sido utilizado frecuentemente con el objeto de asesorar a los legislativos para evitar la convocatoria de una convención constitucional y mantener así el control sobre el proceso de cambio constitucional. Así, a diferencia del caso de Florida, estas comisiones constitucionales no tienen capacidad para proponer enmiendas directamente a la ciudadanía, por lo que es difícil que sus propuestas puedan prosperar en caso de que sean contrarias a la voluntad de la mayoría del legislativo ${ }^{88}$. Como ejemplo histórico, puede tomarse el caso del legislativo de Nueva Jersey, el cual, después de rechazar llamar a una convención constitucional en 1873 y a pesar de que este mecanismo no estaba previsto en la Constitución, nombró una comisión constitucional que planteó toda una serie de reformas constitucionales que el legislativo sometió a consideración de los ciudadanos ${ }^{89}$.

86 Pueden consultarse las reglas de procedimiento aprobadas el 26 de febrero de 2008 en: http://fall. law.fsu.edu/databases/FTBRC/pdf/MasterRulesasamended2_26_08.pdf

87 En el caso de Nuevo México, se establece en el artículo XIX sección 1 de su Constitución, que una «comisión independiente establecida por ley» podrá plantear al legislativo enmiendas constitucionales.

88 Benjamin, «Constitutional Amendment and Revision», p. 192.

89 Williams, R.F., «Are State Constitutional Conventions Things of the Past? The Increasing Role of the Constitutional Commission in State Constitutional Change», Hofstra Law E Policy Symposium, vol. 1, n. ${ }^{\circ} 1,1996$, pp. 1-26. 


\section{CONCLUSIONES}

Como se ha expuesto, menos en el caso de Delaware, todas las constituciones estatales de Estados Unidos requieren que las enmiendas que se introduzcan sean ratificadas mediante referéndum. Las implicaciones prácticas de este hecho son de suma importancia por lo que respecta a la teoría y práctica del derecho constitucional. En primer lugar, lo cual a nuestro entender es de una trascendencia capital en el desarrollo del moderno concepto de Constitución, puesto que si, teóricamente, se defiende que una constitución refleja la voluntad del pueblo en un momento histórico determinado, ello implica, en la práctica, que necesariamente han de establecerse los mecanismos para que esto pueda atestiguarse. El soberano, por lo tanto, en su papel constituyente, debe intervenir directamente, como mínimo, en la fase de ratificación del texto constitucional. En forma muy elegante, Grewal y Purdy señalan que «la concepción de soberanía popular que subyace a una constitución democrática combina necesariamente dos ideas [...] La primera es la autoría popular: que se pueda decir que el pueblo de una manera genuina y no oscurantista es la fuente original de autoridad de su propia ley fundamental. La segunda es el consentimiento presente: que lo que da autoridad a la ley fundamental es el consentimiento de las personas que ahora viven bajo ella» ${ }^{90}$.

Siguiendo con este razonamiento, no puede proceder a reformarse ningún apartado del texto constitucional, por muy secundario que éste pueda ser considerado, sin contar con la aquiescencia directa de la ciudadanía. Como acertadamente comentó el delegado de la Convención Constitucional de Montana de 1972, ya citado en la parte introductoria de este artículo, «toda palabra que esté en [la Constitución] debe ser votada por el pueblo» ${ }^{91}$. De lo contrario, nos encontraríamos con que los destinatarios de los límites que impone la constitución al ejercicio del poder político, se están autolimitando. Constitución y procedimiento democrático están obligatoriamente ligados ${ }^{92}$. La participación en los procesos constituyentes es, en suma, como subraya Tushnet, «el mecanismo contemporáneo para asegurar que una constitución es realmente un ejercicio del poder constituyente» ${ }^{93}$.

Asimismo, como a su vez recuerda Ackerman, en los momentos de cambio constitucional se entra en una fase de «deliberación movilizada» en la que se impulsa un mayor interés ciudadano por la cosa común ${ }^{94}$. De esta forma, el hecho de que las reformas parciales de aspectos no nucleares de la Constitución tengan

90 Singh Grewal, D., Purdy, J., «The Original Theory of Constitutionalism», Yale Law Journal, vol. 127 , n. ${ }^{\circ} 3,2019$, p. 681.

91 Johnstone, «The Constitutional Initiative in Montana», p. 343.

92 Hart, V., «Democratic constitution-making», United States Institute of Peace, n. ${ }^{\circ} 107,2003$, p. 3. p. 2000.

93 Tushnet, M., «Constitution-making: an introduction», Texas Law Review, vol. 91, n. ${ }^{\circ}$ 7, 2013,

94 Ackerman, B., We the people. Foundations.. Cambridge: Harvard University Press, 1991, p. 265. 
también que someterse al escrutinio ciudadano, ha servido para impulsar un debate público en torno a una importante diversidad de cuestiones como el matrimonio entre personas del mismo sexo, la regulación del aborto, la reforma del sistema de responsabilidad extracontractual, la modificación de leyes fiscales, la introducción de la golden rule o la ampliación de la cobertura sanitaria. Este debate público, a su vez, fomenta que la ciudadanía conozca mejor su texto constitucional, herramienta esencial para el ejercicio de sus derechos y el libre desarrollo de las sociedades democráticas $^{95}$. En aquellos estados, además, en que el mecanismo de enmienda constitucional lo puede activar directamente la ciudadanía, se han terminado incluyendo en la agenda política cuestiones que contravienen los intereses o la voluntad de los legisladores ${ }^{96}$. Es el caso, por ejemplo, de la introducción de enmiendas constitucionales en materia de limitación de mandatos de los legisladores estatales. Dichos límites, que actualmente tienen quince estados, fueron, a salvo de dos excepciones, introducidos mediante una enmienda constitucional impulsada por los ciudadanos. Ejemplos similares los podemos encontrar en materia de rediseño de los colegios electorales, la financiación de campañas electorales, autorización de investigación en células madre, el aumento del salario mínimo o el establecimiento de un porcentaje de gasto mínimo en determinados servicios públicos ${ }^{97}$.

Louis Brandeis, quien fuera juez de la Corte Suprema de EEUU, describió a los estados, en una expresión que se ha hecho célebre, como «laboratorios de la democracia» ${ }^{98}$. Los procesos constituyentes y las constituciones estatales previas a la Convención de Filadelfia influyeron decisivamente a través de diversas innovaciones procedimentales y sustanciales en el texto constitucional nacional. En igual sentido, fueron primero los estados los que extendieron el derecho al sufragio a mujeres y afroamericanos o establecieron la elección directa de los senadores, lo que se vio posteriormente reflejado en diferentes enmiendas a la Constitución de EEUU. No obstante, tras una interesante y exitosa experiencia de más de un siglo, en la que las iniciativas populares han contribuido a mejorar la cultura política y democrática y el control sobre los representantes electos, no se ha complementado el artículo $\mathrm{V}$ de la Constitución federal añadiendo la posibilidad de que los ciudadanos puedan plantear directamente enmiendas, tal y como parte de la academia estadounidense

95 Widner, J., «Constitution writing in post-conflict settings: An overview», William E Mary Law Review, vol. 49, n. ${ }^{\circ}$ 4, 2008, p. 1519.

96 Campbell, A.G., «Direct Democracy and Constitutional Reform Campaign: Finance Initiatives in Colorado». En Williams, R.F., TARR, A.G. eds. State Constitutions for the Twenty-first Century, Volume 1: The Politics of State Constitutional Reform. Albany: State University of New York Press, 2006, p. 191.

97 Dinan, «State Constitutional Initiative Processes and Governance in the Twenty-First Century», p. 77.

98 Véase al voto disidente de Brandeis en New State Ice Co. v. Liebmann: «La negación del derecho a experimentar puede estar cargada de graves consecuencias para la nación. Uno de los incidentes felices del sistema federal es que un solo estado, valiente, puede, si sus ciudadanos lo eligen, servir como un laboratorio; y probar nuevos experimentos sociales y económicos sin riesgo para el resto del país». Al respecto puede consultarse Rossen, J., Louis D. Brandeis. American Prophet. New Haven: Yale University Press, 2016, p. 56. 
viene planteado desde hace ya algunos años organizados bajo la National Citizens Initiative for Democracy ${ }^{99}$. Así, mientras que, señalan Bulman-Pozen y Seifter, «las constituciones estatales acogen a un soberano popular activo, la constitución federal ha puesto al soberano popular en coma» ${ }^{100}$. Se termine o no aprobando con el tiempo dicha propuesta de enmienda, la experiencia estatal estadounidense es un excelente ejemplo de las posibilidades de introducción de mecanismos de participación democrática directa en materia de reforma constitucional que cabe tener en cuenta para su posible trasposición a otras latitudes. A ello, además, habrá de sumarse el estudio de otros tantos mecanismos a nivel local y estatal como las iniciativas legislativas populares, el referendo revocatorio de mandato $\left(\right.$ recall $\left.^{101}\right)$, la elección directa de jueces ${ }^{102}$, o los open town meetings, que vienen funcionado ininterrumpidamente en Nueva Inglaterra desde 1633 y que tanto fascinaron a Tocqueville en su viaje por los Estados Unidos ${ }^{103}$.

$$
* * *
$$

TITLE: State constitutional amendment processes in the United States: particularities and mechanisms of citizen participation

ABSTRACT: The purpose of this article is to detail the various mechanisms of constitutional amendment in the state constitutions of the United States. Special emphasis is placed on analyzing the mechanisms of direct popular participation. Constitutionalism, in American theory and practice, is deeply tied to popular participation.

99 La propuesta no es en forma alguna novedosa. La conservadora Federación Estadounidense del Trabajo propuso su introducción en 1913: «Una característica especialmente importante del trabajo de esta liga es promover lo que se conoce como la «Enmienda Gateway», que es un cambio en el método de modificación de la Constitución Federal, para hacerla más fácilmente enmendable. Se propone que una mayoría del Congreso (no como ahora dos tercios), o diez estados, ya sea por acción del legislativo o por voto directo de la gente, pueda proponer enmiendas que deben presentarse, no a las legislaturas estatales como en la actualidad, sino directamente al pueblo de toda la nación para que éste las adopte o rechace en las urnas. Dicha enmienda implicaría el control por parte del pueblo de la Constitución y le permitiría reformarla con las condiciones de seguridad y armonía que requieren los tiempos modernos». Véase american Federation Of Labor, «Initiative, referendum and recall. Warnings concerning «restrictions,» «safeguards,» and «jokers.» Proposed amendments to state constitutions», Report of the Executive council of the American federation of labor to the Seattle, Wash., Convention, p. 12.

100 Bulman-Pozen, J., Seifter, M., «The Democracy Principle in State Constitutions», Columbia Public Law Research Paper, n. ${ }^{\circ}$ 14, 2020, p. 32.

101 Aunque desde una perspectiva más cercana a la ciencia política, es de consulta obligada el trabajo Welp, Y., Serdült, U., La dosis hace el veneno Análisis de la revocatoria del mandato en América Latina, Estados Unidos y Suiza. Quito: Instituto de la Democracia, 2014

102 Dos excepcionales trabajos de obligatoria consulta para quien quiera profundizar en la materia son: Serra Cristóbal, R., «El federalismo judicial estadounidense», Estudios de Deusto: revista de la Universidad de Deusto. 2017, vol. 65, n. ${ }^{\circ}$ 1, pp. 301-330; SERra Cristóbal, R. La selección de jueces en Estados Unidos. Madrid: Thomson Reuters-Civitas, 2011

103 Tocqueville describió los open town meetings de Nueva Inglaterra, con notable asombro, como aquellas instituciones que son «a la libertad lo que las escuelas primarias a la ciencia» puesto que desarrollaban una ciudadanía virtuosa, con todos los miembros de la comunidad responsables y preocupados por el interés general. Véase Tocqueville, A., de. De la démocratie en Amérique. Paris: Institut Coppet, 2012, p. 56. 
RESUMEN: Este artículo tiene por objeto detallar los variados mecanismos de enmienda constitucional en las constituciones estatales de Estados Unidos. Se hace especial énfasis en los mecanismos de participación popular directa. El constitucionalismo, en la teoría y práctica estadounidense, está profundamente ligado a la participación popular.

KEY WORDs: Constitutional reform. Constitutional amendment. Federalism. Participatory democracy. Electoral law.

PalabRas Clave: Reforma constitucional. Enmienda constitucional. Federalismo. Democracia participativa. Derecho electoral.

FECHA DE RECEPCIÓN: 02.06.2020

FECHA DE ACEPTACIÓN: 09.09.2020 
